\title{
A survey of general practitioners' knowledge and clinical practice in relation to valvular heart disease
}

\author{
John P. Birrane ${ }^{1} \cdot$ Zi Lun Lim $^{1}$ - Chee H. Liew ${ }^{2}$. Liesbeth Rosseel ${ }^{1}$. Adrienne Heerey ${ }^{3} \cdot$ Kieran Coleman $^{1,3}$. \\ Joseph Gallagher ${ }^{4}$. Darren Mylotte ${ }^{1} \cdot$ John W. McEvoy ${ }^{1,2}$
}

Received: 15 December 2020 / Accepted: 4 April 2021 / Published online: 24 April 2021

(c) The Author(s) 2021

\begin{abstract}
Introduction General practice has a key role in diagnosing patients with valvular heart disease (VHD) and referring them to appropriate services.

Methods An anonymous survey was conducted to assess the knowledge and clinical practice behaviour of Irish general practitioners (GPs) in relation to VHD. In addition to demographic data, the survey captured information in the following domains: knowledge of VHD prevalence, knowledge of contemporary VHD treatments, barriers to diagnosis, and referral patterns. To augment responses, a monetary prize (donated to charity) was offered and the survey was also disseminated using social media and by the Irish College of General Practitioners.

Results Valid survey responses were received from 197 GPs. The sample was well-balanced by gender, number of years in practice, and practice setting. A small proportion of GPs (16.8\%) used a stethoscope to examine for VHD in all patients over 60 years, a figure that rose to $22.3 \%$ in patients over 75 . Approximately half of participants (48\%) felt confident in their ability to detect and diagnose VHD using a stethoscope, and 74\% felt lack of access to echocardiography was a major barrier to making a VHD diagnosis. There was a high level of awareness among GPs of minimally invasive nonsurgical interventions now available for VHD treatment.

Discussion Irish GPs displayed good understanding of contemporary VHD treatment options but reported low confidence and inconsistent practices in evaluating patients for VHD. Improved access to echocardiography might help address these deficiencies, but reorganisation of services will be required in a resource-limited public health service.
\end{abstract}

Keywords General practice $\cdot$ Primary care $\cdot$ Specialist referral $\cdot$ Valvular heart disease

\section{Introduction}

The prevalence of valvular heart disease (VHD) is increasing in tandem with an aging population and has been described by some commentators as 'the next cardiac epidemic' [1]. The predominant cause of VHD has shifted from rheumatic

John W. McEvoy

johnwilliam.mcevoy@nuigalway.ie

1 University Hospital Galway and SAOLTA University Health Care Group; National University of Ireland, Galway, Ireland

2 National Institute for Prevention and Cardiovascular Health, National University of Ireland Galway, Galway, Ireland

3 Lower Salthill Medical Practice, Salthill, Galway, Ireland

4 Irish College of General Practitioners, Lincoln Place, Dublin 2, Ireland heart disease to degenerative valvular disease, the incidence of which increases with age [2]. Data from the USA indicates a prevalence of moderate to severe VHD in $8.5 \%$ of people aged between 65 and 74, rising to $13.3 \%$ in those aged 75 and over [3]. A UK community screening study of 2500 asymptomatic individuals $>65$ years of age with no previous diagnosis of VHD detected some form of VHD in $50.8 \%$, with $6.4 \%$ being diagnosed with VHD that was deemed clinically significant (moderate or severe) [4]. In another sample of 79,043 symptomatic UK adults referred for echocardiography, 14\% had moderate to severe VHD [5]. This was remarkable given the authors sampled all adults aged 18 years or more. Such findings serve as evidence that VHD is increasingly a major public health problem.

Motivated by the pressing clinical need for VHD treatments among older and/or multimorbid patients, transcatheter-based interventions have recently been developed that 
provide minimally invasive therapeutic options for patients in whom surgical valve replacement (SVR) presents too high a risk. Compelling safety and efficacy data now exist for both transcatheter aortic valve implantation (TAVI) [6-10] in the treatment of aortic stenosis and transcatheter mitral valve repair in the treatment of mitral regurgitation [11]. These successes have spurned the development of promising transcatheter technologies designed to treat other VHD subtypes, like tricuspid regurgitation [12]. In the context of compelling evidence from such clinical trials, a number of tertiary cardiac centres in Ireland now perform transcatheter valve interventions, with outcomes that compare favourably to those observed in US and European registries [13-15].

Patient access to these interventions is dependent on appropriate referral. The European Heart Health Survey, carried out in 2015 and 2017, demonstrated a low level of knowledge about VHD among patients in Europe and low levels of physical examination for VHD by general practitioners (GPs), with both these findings being particularly evident in Ireland $[16,17]$. Therefore, our objective was to survey a cohort of Irish GPs in more detail to obtain a better understanding of their knowledge and practice around VHD. There is also a need to understand the barriers that GPs face in diagnosing VHD, and investigate their patterns of referral to specialist care. By addressing these open questions, our survey may allow Irish health policy makers to better support GPs and hospital systems in caring for patients with VHD.

\section{Methods}

This survey was developed and delivered by Croí and the National Institute for Prevention and Cardiovascular Health (NIPC). Both Croí and the NIPC are not-for-profit organisations based in the West of Ireland. This study was aimed at Irish GPs actively engaged in clinical practice anywhere in the Republic of Ireland. The survey was developed using an iterative process of review and refinement by content experts, representatives of the target population for the survey (GPs), and the primary investigators.

Survey questions were initially developed in consultation with a clinical cardiologist (JWMc) based in Galway University Hospital, a tertiary referral centre serving the west and north-west of Ireland. Questions were designed to assess the most clinically and scientifically important aspects of GP knowledge and practice in relation to VHD. Four GPs (two academic GPs and two community-based GPs) reviewed the questions for clarity and comprehensibility and submitted revisions that were incorporated into subsequent drafts of the survey. The study team then reviewed questions for brevity and concision, aiming for an overall completion time for the survey of $\leq 5 \mathrm{~min}$. A draft survey was piloted at a GP conference on 8 February 2020, which further informed the final survey wording by integrating the feedback from attendees of this conference.

The survey consisted of 15 questions, 3 of which were demographic in nature: GP gender, years of clinical practice ( $<10$ years, $11-25$ years, $>25$ years), and practice setting (city, urban, rural, or mixed). The other survey questions are presented in Tables 1 and 2 and were designed to capture information within the following domains:

- Knowledge of VHD prevalence

- Knowledge of contemporary VHD treatments

- Barriers to diagnosis of VHD

- Referral patterns of patients with suspected VHD

Most survey items presented GPs with a set of responses from which they were to indicate the response that best fit their opinion. For some survey items, we utilised a Likert scale ranging from 'strongly disagree' to 'strongly agree'. Other items asked GPs to choose a range of data that best fit their estimate regarding their own practice or a point of knowledge around VHD.

In preparing this manuscript, we complied with reporting guidelines from the equator-network (www.equator-network. org), focusing in particular on The Checklist for Reporting Results of Internet E-Surveys (CHERRIES) [18].

\section{Recruitment of participants}

The survey was hosted on the SurveyMonkey platform. The NIPC has 175 GPs as 'alliance members' (an affiliate subscription membership that grants access to educational content produced by the NIPC) and these members were invited by email to complete the survey. A total of 152 GPs who had attended an NIPC webinar in July 2020 were also invited to complete the survey. In addition, the survey was disseminated by the Irish College of General Practitioners (the professional and training body for GPs) by inclusion within an ebulletin to their members. Furthermore, the Health Service Executive (HSE; the organisational body in charge of running the public health service in Ireland) emailed a link for the survey to GPs providing general medical services to public patients. Finally, the survey was circulated on social media (WhatsApp, Twitter, LinkedIn). GPs were encouraged to participate by offering entry into a draw for a donation of five hundred euros to be made to a charity of their choice.

\section{Statistical analysis}

All survey data were exported from the SurveyMonkey platform to Microsoft Excel. Further statistical analysis was carried out using SPSS Version 26 (IBM, Armonk, New York). Categorical responses were reported as 
Table 1 Survey items and responses

Survey item $\quad$ Responses $n(\%)$

1.1 Knowledge and practice related to valvular heart disease

1 I feel confident that I can detect and diagnose moderate to severe valvular heart disease with my stethoscope (i.e., no echocardiography)

Strongly disagree $\quad 17(8.6)$

Disagree $\quad 45(22.8)$

Neither agree nor disagree $\quad 36(18.3)$

Agree

$91(46.2)$

Strongly agree

2 Based on your clinical experience, is it worthwhile asking for salient symptoms in the for the detection of valvular heart disease?

No, the symptoms are too nonspecific and vague

Yes, but taking a full history for all heart valve symptoms is only useful among patients who first complain of symptoms suggestive of heart valve disease

Yes, all patients over 60 should be routinely screened for heart $88(45.1)$ valve symptoms

3 In my clinical practice of patients $>60$ years, I do a stethoscope examination to screen for valvular heart disease among asymptomatic patients

All the time

$>50 \%$ of the time

$<50 \%$ of the time

Never

$24(12.2)$

4 In my clinical practice of patients $>75$ years, I do a stethoscope examination to screen for valvular heart disease among asymptomatic patients

All the time

$44(22.3)$

$>50 \%$ of the time

$85(43.1)$

$<50 \%$ of the time

$48(24.4)$

Never

$20(10.2)$

5 Based on your clinical experience, what do you think the

$0-5 \%$

$63(32)$

prevalence is of moderate or severe valvular heart disease in Irish adults between 60 and 74 years?

$>5-10 \%$

$70(35.5)$

$>10-20 \%$

$54(27.4)$

$>20 \%$

$10(5.1)$

$0-5 \%$

$12(6.1)$

67 (34)

prevalence is of moderate or severe valvular heart disease in $>5-10 \%$

69 (35)

Irish adults $\geq 75$ years

$>10-20 \%$

1.2 Referral patterns and barriers to VHD diagnosis

8 What do you see as being the barriers to diagnosing valvular heart disease?

Lack of direct access to echocardiography

Waiting times for outpatient appointment

Patient unable to attend outpatients

9 What percentage of patients with suspected asymptomatic

Less than $50 \%$ valvular heart disease do you refer for a specialist opinion or echocardiography?

\section{0 to $75 \%$}

More than $75 \%$

$100 \%$

1.3 Knowledge regarding valvular intervention

10 An elderly patient ( $>75$ years) with severe valvular heart disease must be able to undergo general anaesthesia and major surgery to be treated and those that cannot are not suitable for referral to a specialist

Strongly disagree

Disagree

Neither agree nor disagree $16(8.2)$

Agree

Strongly agree

11 The only treatment for severe symptomatic heart valve disease is surgical replacement of the valve

Agree

12 Frail patients and/or patients aged over 90 years are not candidates for heart valve replacement

Agree

numbers and proportions. Continuous/numerical responses we reported as means and standard deviations. When comparing categorical responses between the various demographic groups, we used chi-squared testing. We considered a two-sided $p<0.05$ as statistically significant. 
Table 2 GP perceptions on the relative importance of screening for VHD and other cardiovascular disease (question 7 in the survey)

\begin{tabular}{|c|c|c|}
\hline & & Mean rank $(S D)$ \\
\hline \multirow{5}{*}{$\begin{array}{l}\text { Based on your clinical experience of patients over } 60 \text { years, please rank in order of importance } \\
\text { from } 1 \text { (most important) to } 5 \text { (least important), the need to screen for the following medical } \\
\text { conditions }\end{array}$} & Hypertension & $1.71(1.08)$ \\
\hline & Atrial fibrillation & $2.28(.84)$ \\
\hline & Diabetes & $2.46(.93)$ \\
\hline & Heart valve disease & $4.04(.73)$ \\
\hline & Abdominal aortic aneurysm & $4.51(.96)$ \\
\hline
\end{tabular}

\section{Results}

In total, 199 survey responses were obtained. One participant's data were excluded as he/she only responded to 1 of the 15 survey questions. Two consecutive responses on the same date were noted to have identical answers to each of the survey questions, raising suspicion of a duplicate. Data from one of these responses were excluded leaving 197 unique respondents for analysis. Owing to the use of varying approaches in disseminating the invitation for this survey (described in the 'Methods' section), inclusive of social media advertisements, is not possible to know exactly how many GPs reviewed the invitation to participate in our survey. Therefore, we are unable to accurately report a survey response rate.

Responses for each survey item are presented in Tables 1 and 2. Demographic characteristics of the survey participants are described in Table 3, demonstrating that the study sample was balanced in terms of sex, years of experience, and practice setting.

\section{GP knowledge and practice}

Survey responses indicated that $16.2 \%$ of GPs always examined patients older than 60 for VHD with a stethoscope,
Table 3 Demographic data of survey participants $(N=197$ General Practitioners)

\begin{tabular}{ll}
\hline & $n(\%)$ \\
\hline $\begin{array}{l}\text { Years' experience } \\
<10 \text { years }\end{array}$ & $61(31)$ \\
11-25 years & $63(32)$ \\
$>$ 25 years & $73(37)$ \\
Gender & \\
Men & $94(48)$ \\
Women & $102(52)$ \\
GP practice & \\
City & $51(26)$ \\
Urban & $35(17.9)$ \\
Rural & $50(25.5)$ \\
Mixed & $60(30.6)$ \\
\hline
\end{tabular}

a figure which increased to $22.3 \%$ in patients older than 75 years (Fig. 1). The proportion of GPs who never examined for VHD with a stethoscope was $12.2 \%$ for patients $>60$ years and $10.2 \%$ for patients $>75$ years. The proportion of GPs who examined patients with a stethoscope $>50 \%$ and $<50 \%$ of the time was similar whether they were $>60$ years or $>75$ years.

Most GPs correctly identified that the prevalence of VHD increases with age (Fig. 2), though the actual prevalence estimates varied widely among respondents and often differed from the correct values reported in the literature (which document a prevalence of moderate-severe VHD of $5-10 \%$ among adults $60-74$ years old and $10-20 \%$ among adults aged 75 or older).

Approximately half of GPs surveyed (50.3\%) reported confidence in detecting and diagnosing moderate-severe VHD by auscultation of the praecordium with a stethoscope. By contrast, $31.4 \%$ reported that they were not confident in diagnosing VHD with a stethoscope, while $18.3 \%$ of doctors were uncertain in their diagnostic ability. We found no difference in reported confidence in detecting and diagnosing VHD with stethoscope examination in GPs that had been practicing for $\leq 25$ years or $>25$ years (Fig. 3). The vast majority (87.7\%) of GPs agreed that asking for salient symptoms was important for the detection of VHD, but only $45 \%$ reported doing so routinely in patients $\geq 60$ years old.

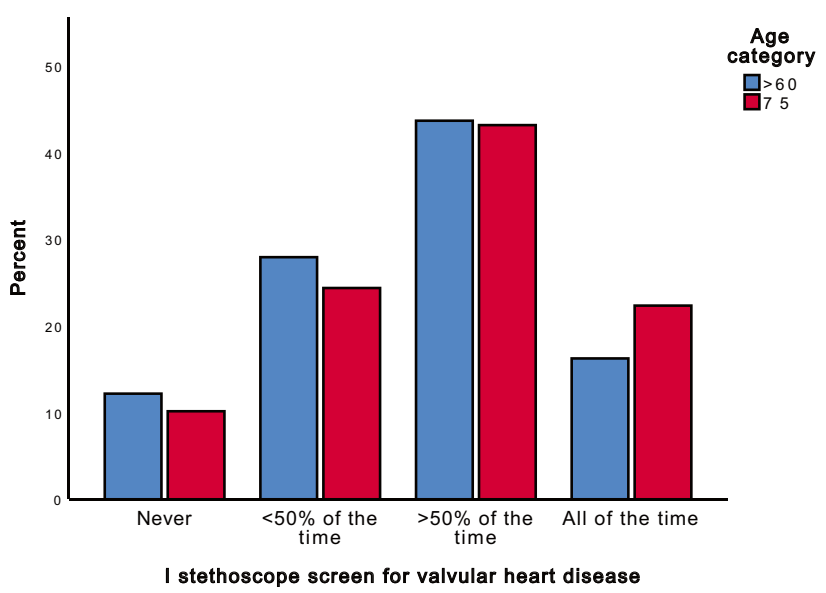

Fig. 1 Frequency of stethoscope screening by GPs, by age category 


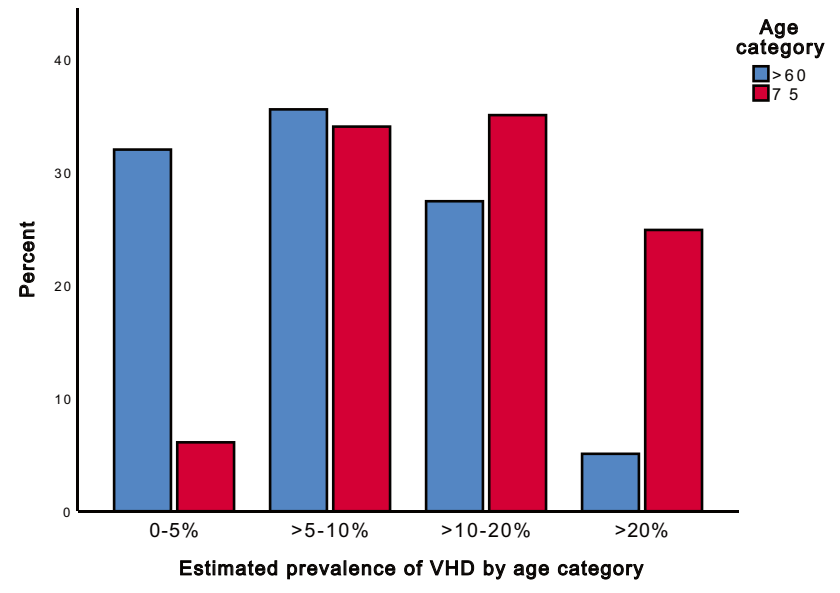

Fig. 2 Estimated prevalence of VHD by age category

We also asked GPs to rank the importance of screening for VHD relative to four other common cardiovascular conditions (Table 2). GPs ranked hypertension, atrial fibrillation, and diabetes, in that order, ahead of valvular heart disease in relative importance for screening. Valvular heart disease $(M=4.04, S D=0.73)$ was ranked slightly ahead of abdominal aortic aneurysms $(M=4.51, S D=0.96)$ as a priority for screening.

\section{Referral patterns and barriers to diagnosis of VHD}

Three quarters of Irish GPs reported that a lack of access to echocardiography was a barrier to diagnosing VHD in their patients. Moreover, $23.5 \%$ indicated that waiting times for specialist outpatient appointments were also considerable barriers to VHD detection in their practice. Despite this, almost $70 \%$ of GPs nevertheless reported sending the majority of asymptomatic patients that they suspected of VHD for echocardiography or a specialist opinion.

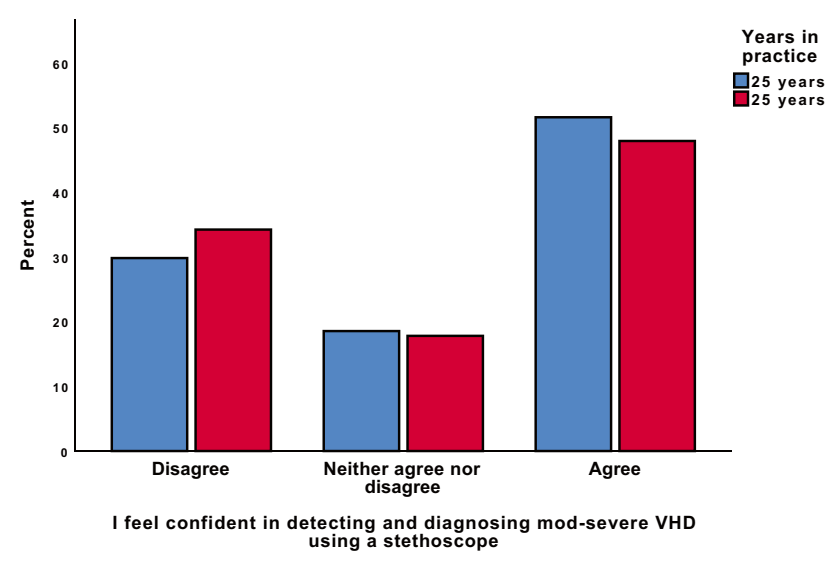

Fig. 3 Confidence in diagnosing VHD with a stethoscope divided by years in practice

\section{Knowledge regarding VHD intervention}

Most GPs felt that a patient with severe VHD unable to tolerate general anaesthesia or open-heart surgery could still benefit from a specialist opinion. Two-thirds $(66.8 \%)$ of GPs disagreed that SVR was the only intervention for severe symptomatic VHD, indicating a familiarity with less invasive approaches. Just 25 (12.8\%) of GPs believed that SVR was the only intervention for their patients with VHD. Similarly, $50 \%$ disagreed with a statement that frail patients or those older than 90 years were not candidates for valve replacement compared with $23 \%$ who agreed (thereby indicating that half were aware of less invasive valve replacement options for the frail and very old).

When survey responses were subdivided by demographic factors (Table 4; Fig. 4), a slightly higher number of GPs from rural and mixed practices indicated an awareness that older and frail patients are eligible for valve replacements, that there were less-invasive alternatives to SVR, and that severe symptomatic VHD patients who were not surgical candidates should still be referred for specialist opinion. A chi-squared analysis of these responses indicated a significant difference $(p=0.03)$ in the responses of GPs to question number 10 (see Table 1), where GPs were asked if they agreed there were alternatives to SVR in a frail, multimorbid patient. However, inspection of the standardised residuals revealed that this difference lay predominantly in the proportion of GPs who were unsure.

We also investigated whether years of experience was associated with GPs' awareness of newer, less invasive interventions, hypothesising that more recently trained GPs may have encountered transcatheter valve interventions during hospital rotations, prior to entering full-time GP practice. For the purpose of this analysis, we divided GPs according to whether they had greater than or equal to 25 years of experience, and those who had less than 25 years' experience. A higher proportion of the more experienced GP group (53.4\%) correctly noted that frail or older patients may be candidates for valve replacement in the current era of less invasive therapeutic interventions, compared with GPs in the lower experience group (48\%), a finding that was statistically significant $\left(\chi^{2}(2)=6.08\right.$, $p=0.048$ ) (Table 4).

\section{Discussion}

We note the following observations from our survey of Irish GPs: (1) Only $50 \%$ of GPs were confident they could detect and diagnose VHD using a stethoscope. (2) Only $45 \%$ of GPs agree that symptoms of VHD should be routinely queried among patients $>60$ years old. (3) GPs correctly recognised that VHD prevalence increases with age, but many 
Table 4 Knowledge regarding valvular intervention, divided by urban and rural practitioners, and by years of experience

\begin{tabular}{|c|c|c|c|c|c|}
\hline & & $\begin{array}{l}\text { Urban/mixed } \\
n(\%)\end{array}$ & $\begin{array}{l}\text { Rural } \\
n(\%)\end{array}$ & $\begin{array}{l}\leq 25 \text { years } \\
n(\%)\end{array}$ & $\begin{array}{l}>25 \text { years } \\
n(\%)\end{array}$ \\
\hline \multirow{4}{*}{$\begin{array}{l}\text { An elderly patient ( }>75 \text { years) with severe valvular heart } \\
\text { disease must be able to undergo general anaesthesia and } \\
\text { major surgery to be treated and those that cannot are not } \\
\text { suitable for referral to a specialist }\end{array}$} & Agree & $7(8.1)$ & $7(6.4)$ & $8(6.5)$ & $6(8.2)$ \\
\hline & Not sure & $12(14)$ & $4(3.7)$ & $13(10.6)$ & $3(4.1)$ \\
\hline & Disagree & $67(77.9)$ & $98(89.9)$ & $102(82.9)$ & $64(87.7)$ \\
\hline & & $\chi^{2}(2)=7.21, p=0.03$ & & $\chi^{2}(2)=2.65, p=0.27$ & \\
\hline \multirow{4}{*}{$\begin{array}{l}\text { The only treatment for severe symptomatic heart valve } \\
\text { disease is surgical replacement of the valve. Please choose } \\
\text { from the options below: }\end{array}$} & Agree & $12(14)$ & 13 (11.9) & $11(8.9)$ & $14(19.2)$ \\
\hline & Not sure & $17(19.8)$ & $22(20.2)$ & $25(20.3)$ & $15(20.5)$ \\
\hline & Disagree & $57(66.3)$ & $74(67.9)$ & $87(70.7)$ & $44(60.3)$ \\
\hline & & $\chi^{2}(2)=.18, p=.92$ & & $\chi^{2}(2)=4.51, p=.11$ & \\
\hline \multirow{4}{*}{$\begin{array}{l}\text { Frail patients and/or patients aged over } 90 \text { years are not } \\
\text { candidates for heart valve replacement. Please choose one } \\
\text { of the options below: }\end{array}$} & Agree & $22(25.6)$ & $23(21.1)$ & $35(28.5)$ & $10(13.7)$ \\
\hline & Not sure & $22(25.6)$ & $31(28.4)$ & 29 (23.6) & $24(32.9)$ \\
\hline & Disagree & $42(48.8)$ & $55(50.5)$ & $59(48)$ & $39(53.4)$ \\
\hline & & $\chi^{2}(2)=.59, p=0.75$ & & $\chi^{2}(2)=6.08, p=0.05$ & \\
\hline
\end{tabular}

under- or over-estimated of the true prevalence of VHD, the best estimate for which is $5-10 \%$ in patients $65-74$ years old and $10-20 \%$ in those older than $75[3,4]$. (4) While less than a quarter of GPs reported routine use of a stethoscope exam to examine for VHD among patients $\geq 60$ years old, GPs were more likely to examine all patients $\geq 75$ years of age. And (5) GPs appeared to demonstrate excellent knowledge
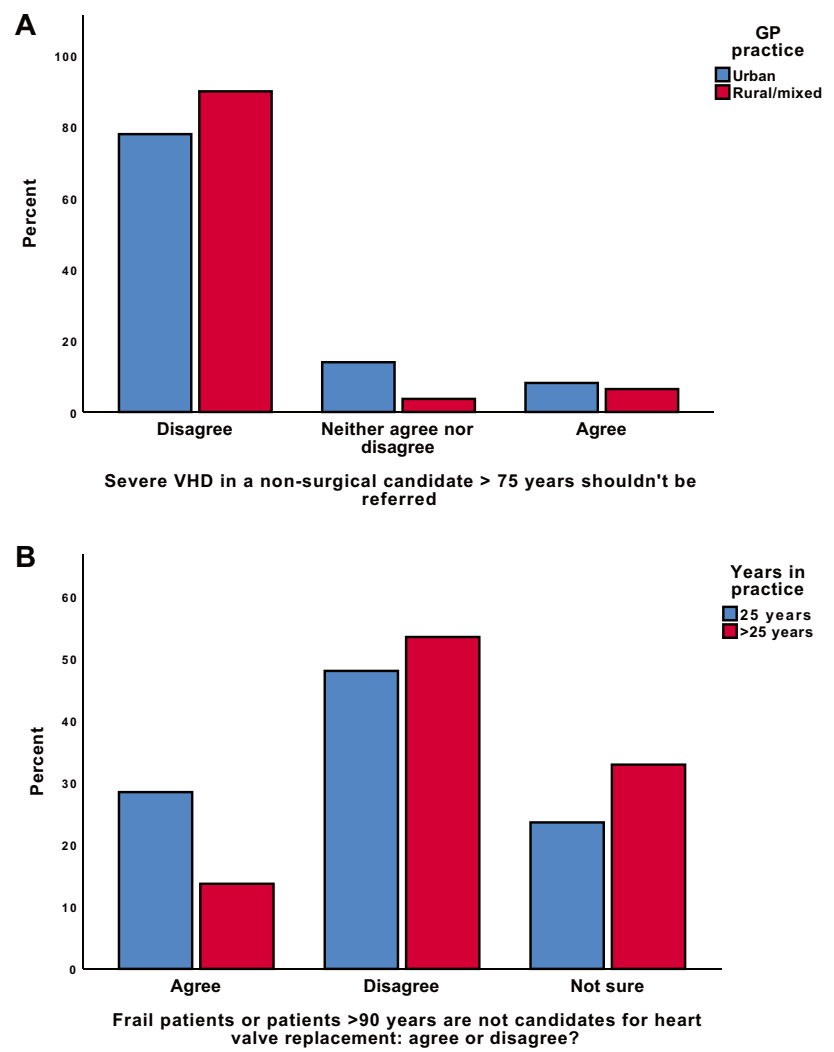

Fig. 4 Differences in knowledge of intervention in VHD on the basis of selected demographic subgroups. a Responses based on location of GP practice. $\mathbf{b}$ Responses based on years in practicecxs of newer therapeutic options for VHD and recognised that frail and older patients should still be referred for specialist opinion given the contemporary availability of less invasive therapeutic interventions.

Our survey also demonstrates that there is concordance between GPs' self-reported practice with respect to VHD and the previously surveyed experience of Irish patients. The previously published finding that $68 \%$ of Irish patients over 60 years infrequently had their chest examined with a stethoscope [16, 17] is broadly consistent with our finding that $27.9 \%$ of GPs reported examining patients $\geq 60$ years with a stethoscope exam less than half of the time and that $12.2 \%$ of them reported never doing so. Furthermore, our survey indicates that this may be related to the low levels of self-reported confidence among GPs in their ability to detect and diagnose VHD by physical examination.

Previous research into the accuracy of physical examination in detecting and diagnosing VHD have reported conflicting results owing to heterogeneity of the doctor and patient characteristics of the cohorts studied. A 2016 review presented supporting evidence for the value of physical examination in the diagnosis of VHD, but many of the cited studies featured cardiologists as the examining doctors [19]. By contrast, a 2018 study of GPs found that the sensitivity of cardiac auscultation for diagnosing VHD in asymptomatic patients was poor (44\% for clinically significant VHD) when conducted within a large, community-based screening programme [20].

While physical examination is an accessible and inexpensive method for the detection of murmurs resulting from VHD, in addition to facilitating the bond between doctor and patient [21], echocardiography is the gold standard for the diagnosis of VHD and for the quantification of the severity of the condition. About $74 \%$ of GPs in this survey reported a lack of direct access to echocardiography as being a barrier 
to diagnosing VHD. Initiatives to increase the availability of echocardiography in the community are in the process of being implemented in Ireland as part of the Slaintecare programme [22]. Judging by the results of this study, such initiatives will be welcomed by GPs. We look forward, in time, to research detailing their effects on community-based diagnosis and management of VHD.

Ultrasound and echocardiography are increasingly a feature of modern medical school curricula [23]. A number of studies have demonstrated satisfactory acquisition of ultrasound skills among medical students and enhancement of diagnostic accuracy after training with the technology [24-28]. Opportunistic screening (i.e., case-finding) using focused point-of-care ultrasound by GPs may represent a means of enhancing detection rates in the primary care environment. Full departmental echocardiograms could then be reserved for cases with higher indexes of suspicion or provisional abnormalities detected by GPs at the point-of-care. Such an approach could plausibly reduce waiting times for outpatient echocardiography and ensure that urgent cases were detected in good time, particularly given GPs' low confidence in diagnosing VHD using stethoscope alone. Based in part on our survey results, professional bodies responsible for the continuing professional development of GPs might consider applying established medical school curricula to educational offerings designed for the up-skilling of interested GPs in point-of-care ultrasound of the heart. Whether such efforts are practical requires investigation. Alternatively, new artificial intelligence techniques offer the potential to augment the GP's ability to diagnose VHD using the stethoscope [29, 30].

Awareness among GPs regarding alternatives to surgical replacement of diseased valves was generally high in this survey. This is an important and encouraging result from our survey because new transcatheter valvular interventions have removed a significant barrier to effective treatment among patients who cannot tolerate general anaesthesia or open heart surgery. Nonetheless, further education of GPs regarding these new technologies is motivated by the finding that $12.8 \%$ of the sample appeared to not recognise that there were alternatives to traditional open-heart surgery. A significant minority of GPs (23\%) also did not agree that frail patients and/or patients aged over 90 years were candidates for heart valve replacement. Interestingly, GPs from rural and mixed settings appeared more likely to indicate an awareness that less invasive therapeutic interventions are now available to older, frail patients. This might reflect a greater familiarity with the older patient cohorts generally found in rural settings [31], and experience of their patients having had successful intervention.

Limitations of the present study include the fact that the sample of GPs was self-selected. Owing to the methods of dissemination deployed, which included web-based dispersal of a web link to the survey, we were unable to calculate an accurate response rate for the study. This is because the denominator number of how many GPs actually read the invitation (whether or not they participated) was impossible to determine. On the basis of the demographic characteristics observed; however, we had a good representation of GPs across age, gender, and practice setting. Another limitation is that a small proportion of GPs who responded completed the survey after a webinar that included a talk on VHD. Therefore, knowledge levels may have been higher in our respondents compared to a sample of GPs who have not recently undertaken a continuing professional development in cardiology. Finally, it is possible in retrospect that the wording for question number 1 caused confusion among some GPs in that they may have taken the question to relate to 'any' form of moderate to severe VHD or they may have interpreted the question to ask about their confidence in diagnosing a specific subtype of VHD (e.g. mitral stenosis vs mitral regurgitation vs other).

In conclusion, we observed low confidence and inconsistent practices in the evaluation of VHD in this sample of Irish GPs. On a more positive note, respondents demonstrated an awareness regarding the association of increasing age with VHD and good knowledge regarding contemporary treatment options. Improved access to echocardiography, either at the point of care in the form of limited ultrasound examinations or in the hospital/cardiology clinic in the form of full examinations, along with the development of a structured approach to evaluating patients for VHD has the potential to enhance its detection and diagnosis in the community.

Funding Open Access funding provided by the IReL Consortium

\section{Declarations}

Ethics approval and consent to participate The survey was completely voluntary and participants' consent was implied by their completion of the survey. No formal ethics were sought, as no identifying information was sought from participants and no sensitive or personal information was sought.

Disclosures This is an investigator-initiated (JWMc) survey supported by Croí, the West of Ireland Heart and Stroke Charity. Croí are funded by charitable donations from the community and by philanthropic support from Industry sponsors, which include Edwards Life Sciences. Neither the study investigators nor participating GPs received any personal financial renumeration for their involvement in this survey.

Open Access This article is licensed under a Creative Commons Attribution 4.0 International License, which permits use, sharing, adaptation, distribution and reproduction in any medium or format, as long as you give appropriate credit to the original author(s) and the source, provide a link to the Creative Commons licence, and indicate if changes were made. The images or other third party material in this article are included in the article's Creative Commons licence, unless indicated otherwise in a credit line to the material. If material is not included in the article's Creative Commons licence and your intended use is not 
permitted by statutory regulation or exceeds the permitted use, you will need to obtain permission directly from the copyright holder. To view a copy of this licence, visit http://creativecommons.org/licenses/by/4.0/.

\section{References}

1. D'Arcy JL, Prendergast BD, Chambers JB (2011) Valvular heart disease: the next cardiac epidemic? Heart 97:1112. https://doi.org/ 10.1136/hrt.2010.205096corr 1

2. Andell P, Li X, Martinsson A et al (2017) Epidemiology of valvular heart disease in a Swedish nationwide hospital-based register study. Heart 103:1696-1703. https://doi.org/10.1136/heartjnl-2016-310894

3. Nkomo VT, Gardin JM, Skelton TN et al (2006) Burden of valvular heart diseases: a population-based study. Lancet 368:10051011. https://doi.org/10.1016/S0140-6736(06)69208-8

4. D'Arcy JL, Coffey S, Loudon MA et al (2016) Large-scale community echocardiographic screening reveals a major burden of undiagnosed valvular heart disease in older people: the OxVALVE Population Cohort Study. Eur Heart J 37:3515-3522a. https://doi. org/10.1093/eurheartj/ehw229

5. Marciniak A, Glover K, Sharma R (2017) Cohort profile: prevalence of valvular heart disease in community patients with suspected heart failure in UK. BMJ Open 7:1-4. https://doi.org/10. 1136/bmjopen-2016-012240

6. Leon MB, Smith CR, Mack MJ et al (2016) Transcatheter or surgical aortic-valve replacement in intermediate-risk patients. N Engl J Med 374:1609-1620. https://doi.org/10.1056/NEJMoa1514616

7. Svensson LG, Ph D, Tuzcu EM et al (2016) Transcatheter aortic-valve implantation for aortic stenosis in patients who cannot undergo surgery. N Engl J Med 363:1511-1520. https:// doi.org/10.1056/NEJMoa1602001

8. Mack MJ, Leon MB, Thourani VH et al (2019) Transcatheter aortic-valve replacement with a balloon-expandable valve in lowrisk patients. N Engl J Med 380:1695-1705. https://doi.org/10. 1056/NEJMoa1814052

9. Popma JJ, Michael Deeb G, Yakubov SJ et al (2019) Transcatheter aortic-valve replacement with a self-expanding valve in low-risk patients. N Engl J Med 380:1706-1715. https://doi.org/10.1056/ NEJMoa1816885

10. Makkar RR, Thourani VH, Mack MJ et al (2020) Five-year outcomes of transcatheter or surgical aortic-valve replacement. N Engl J Med 382:799-809. https://doi.org/10.1056/NEJMoa1910555

11. Stone GW, Lindenfeld JA, Abraham WT et al (2018) Transcatheter mitral-valve repair in patients with heart failure. N Engl J Med 379:2307-2318. https://doi.org/10.1056/NEJMoa1806640

12. Taramasso M, Benfari G, van der Bijl P et al (2019) Transcatheter versus medical treatment of patients with symptomatic severe tricuspid regurgitation. J Am Coll Cardiol 74:2998-3008. https://doi. org/10.1016/j.jacc.2019.09.028

13. Dowling C, Firoozi S, Doyle $\mathrm{N}$ et al (2019) Initial experience of a large, self-expanding, and fully recapturable transcatheter aortic valve: the UK \& Ireland Implanters' registry. Catheter Cardiovasc Interv 93:751-757. https://doi.org/10.1002/ccd.27934

14. Tanner R, Moran B, Margey R et al (2020) Clinical experience with trans-catheter aortic valve implantation at a tertiary hospital in the Republic of Ireland. Ir J Med Sci 189:139-148. https://doi. org/10.1007/s11845-019-02030-7

15. Bajrangee A, Coughlan JJ, Teehan S et al (2017) Early and mid-term outcomes after transcatheter aortic valve implantation (TAVI) in Ireland. IJC Hear Vasc 16:1-3. https://doi.org/10. 1016/j.ijcha.2017.06.001
16. Gaede L, Aarberge L, Brandon Bravo Bruinsma G et al (2019) Heart Valve Disease Awareness Survey 2017: what did we achieve since 2015? Clin Res Cardiol 108:61-67. https://doi.org/10.1007/ s00392-018-1312-5

17. Croi (2020) Irish valve survey | Croi Heart \& Stroke Charity. https://croi.ie/tag/irish-valve-survey/. Accessed 26 Sep 2020

18. Sekeres MA, Elson P, Kalaycio ME et al (2009) Time from diagnosis to treatment initiation predicts survival in younger, but not older, acute myeloid leukemia patients. Blood 113:28-36

19. Elder A, Japp A, Verghese A (2016) How valuable is physical examination of the cardiovascular system? BMJ $354 \mathrm{https}: / /$ doi. org/10.1136/bmj.i3309

20. Gardezi SKM, Myerson SG, Chambers J et al (2018) Cardiac auscultation poorly predicts the presence of valvular heart disease in asymptomatic primary care patients. Heart 1832-1835 https:// doi.org/10.1136/heartjnl-2018-313082

21. Jan MF, Tajik AJ (2020) Auscultatory interregnum-bicentennial of the stethoscope. Circulation 142:715-716. https://doi.org/10. 1161/CIRCULATIONAHA.120.046430

22. Saolta University Healthcare Group (2020) New Cardiology Services rolled out to Primary Care Centres in Galway and Roscommon as part of Sláintecare I Saolta University Health Care Group. https://www.saolta.ie/news/new-cardiology-services-rolled-outprimary-care-centres-galway-and-roscommon-part-sláintecare. Accessed 6 Mar 2021

23. Birrane J, Misran H, Creaney M et al (2018) A scoping review of ultrasound teaching in undergraduate medical education. Med Sci Educ 28:45-56. https://doi.org/10.1007/s40670-017-0491-4

24. DeCara JM, Kirkpatrick JN, Spencer KT et al (2005) Use of hand-carried ultrasound devices to augment the accuracy of medical student bedside cardiac diagnoses. J Am Soc Echocardiogr 18:257-263. https://doi.org/10.1016/j.echo.2004.11.015

25. Yan BP, Fok JCY, Wong THY et al (2018) Junior medical student performed focused cardiac ultrasound after brief training to detect significant valvular heart disease. IJC Hear Vasc 19:41-45. https:// doi.org/10.1016/j.ijcha.2018.03.007

26. Panoulas VF, Daigeler AL, Malaweera ASN et al (2013) Pocket-size hand-held cardiac ultrasound as an adjunct to clinical examination in the hands of medical students and junior doctors. Eur Heart J Cardiovasc Imaging 14:323-330. https:// doi.org/10.1093/ehjci/jes140

27. Stokke TM, Ruddox V, Sarvari SI et al (2014) Brief group training of medical students in focused cardiac ultrasound may improve diagnostic accuracy of physical examination. J Am Soc Echocardiogr 27:1238-1246. https://doi.org/10.1016/j.echo.2014.08.001

28. Shmueli H, Burstein Y, Sagy I et al (2013) Briefly trained medical students can effectively identify rheumatic mitral valve injury using a hand-carried ultrasound. Echocardiography 30:621-626. https://doi.org/10.1111/echo.12122

29. Lai LSW, Redington AN, Reinisch AJ et al (2016) Computerized automatic diagnosis of innocent and pathologic murmurs in pediatrics: a pilot study. Congenit Heart Dis 11:386-395. https:// doi.org/10.1111/chd.12328

30. Thompson WR, Reinisch AJ, Unterberger MJ, Schriefl AJ (2019) Artificial intelligence-assisted auscultation of heart murmurs: validation by virtual clinical trial. Pediatr Cardiol 40:623-629. https://doi.org/10.1007/s00246-018-2036-z

31. Office CS (2020) Ages at urban, rural and county level. In: Census Popul. 2016 - Profile 3 An Age Profile Irel. https://www.cso.ie/ en/releasesandpublications/ep/p-cp3oy/cp3/urr/. Accessed 4 Nov 2020 